\title{
Disability in young people and adults after head injury: 12-14 year follow-up of a prospective cohort
}

\author{
Thomas M McMillan, Graham M Teasdale, Elaine Stewart
}

\section{See Editorial commentary, p 1036}

Institute of Health and Wellbeing, University of Glasgow, Glasgow, UK

\section{Correspondence to} Professor T M McMillan, Institute of Health and Wellbeing, University of Glasgow, Gartnavel Royal Hospital, 1055 Great Western Road, Glasgow G12 OXH, UK; thomas.mcmillan@glasgow.ac. uk

Received 15 March 2012 Revised 19 April 2012 Accepted 22 April 2012

Published Online First 29 May 2012

\author{
ABSTRACT \\ Background There is a need to establish how long term \\ outcome evolves after head injury (HI) and factors \\ related to this, to inform opportunities for intervention. \\ Objective To determine late outcome in adults \\ 12-14 years after hospital admission for $\mathrm{HI}$ and to \\ examine relationships between injury, early and late \\ factors, and disability.
}

Methods A prospective cohort with $\mathrm{HI}$, whose outcome was reported previously at 1 and $5-7$ years after injury, were followed up after 12-14 years. Participants were assessed using structured and validated measures of disability (Glasgow Outcome Scale-Extended), psychological well being, alcohol use and health status. Results Of 219 survivors followed-up at $5-7$ years, 34 $(15.5 \%)$ had died by $12-14$ years. Disability remained common in survivors at $12-14$ years $(51 \%)$, as found at 1 and $5-7$ years (53\%). For those disabled at 1 year, outcome was poor, with $80 \%$ dead or disabled at 12-14 years. Older age at injury, a premorbid history of brain illness or physical disability and post-injury low self-esteem and stress were associated with disability at 12-14 years. Disability changed between $5-7$ and $12-14$ years in $55 \%$ of survivors, improving in $23 \%$. Late changes in disability between $5-7$ and $12-14$ years were associated with self-perceptions of locus of control as being 'powerful others' at 5-7 years.

Conclusions Disability is common 12-14 years after hospital admission with a HI. For some there is a dynamic process of change in disability over time that is associated with self-perceptions of control that could be a target for intervention based research.

\section{INTRODUCTION}

The risk that a head injury can be followed by disability is well recognised. Nevertheless, there is little reliable information about the late burden of disability and how outcome alters over time, either in a representative cohort or, especially, in individual victims. ${ }^{12}$ This is because most studies have considered only selected populations, such as severe head injury, and very few consider change over time in terms of cognitive, emotional and injury factors in the same people. ${ }^{2}$ These studies tend to be cross sectional and consider outcome at a single point in time, often with an extensive range of intervals after injury that in some studies span 30 years. ${ }^{3-7}$ Studies of this kind may be insensitive to differences in outcome within narrower time periods and can also rely on retrospectively collected data, including regarding hospital admission, which can be invalid. As there are very few studies that prospectively consider change over time, it is not clear when there can be an expectation of improvement, of worsening or of little change in outcome. Furthermore, no study has been able to investigate if features found at one time point relate to whether or not changes will have occurred several years later.

One study followed-up people with severe head injury at a single time point, grouping cases into 5 or 10 or 15 years since injury. They found a poorer outcome in terms of emotional control, cognition and life satisfaction in those with cerebral lesions and emphasised the importance of family and social support on long term outcome. ${ }^{8}$ Ponsford et $a l^{9}$ followed up 60 of 302 people with head injury admitted for rehabilitation and found associations between disability 10-12 years after injury and original PTA duration, pre-injury education, poorer cognitive function and self-report of anxiety. Thomsen ${ }^{10}$ compared outcome at 5 months, 2-5 years and 10-15 years in the same 40 severe head injuries. Psychosocial problems were persistent and more debilitating than physical problems in this interesting descriptive study. A study that focused on employment outcome in 64 people $2-6$ years and 10-15 years after severe head injury found little change in work status more than 2 years after injury. ${ }^{11}$ In fact very few studies consider changes in disability in the same individuals at different time points, and hence miss the important fact that although disability persists for many, some improve and some deteriorate over time. ${ }^{2} 12$

The Hospitalised Head Injury Study prospectively identified admissions to Glasgow hospitals over a 12 -month period. ${ }^{1}{ }^{2}$ An important factor in the original design was the inclusion of all hospital admissions, without limit of age or exclusions in terms of severity of head injury. Our earlier followups of this cohort note surprisingly high rates of death up to 13 years after injury ${ }^{13} 14$ and persisting disability and change in disability status in a high proportion of cases between 1 and 5-7 years after injury. The aim of the present study is to describe disability outcomes in this cohort 12-14 years after injury and how these compare to outcomes at earlier follow-ups. We also explore the relationships between features found at the time of injury or at follow-up for up to 5-7 years after injury and outcomes at $12-14$ years.

\section{METHODS}

Between February 1995 and February 1996, the Hospitalised Head Injury Study cohort was recruited from all acute general hospitals in Glasgow. ${ }^{1}$ It considered all adults admitted because of a head 
injury, irrespective of severity or previous history. All of those with a moderate (Glasgow Coma Scale (GCS) score 9-13) or severe head injury (GCS 3-8) and a sample of those with a mild injury (GCS 13-15) who were representative of the population (in terms of age, gender, cause of injury, previous history of head or brain injury, or having physical limitations) were followed-up at 1 year and $5-7$ years after injury. ${ }^{12}$ The present study provides further follow-up 12-14 years after injury.

Tracing of patients used the last known general practitioner (GP) address, supplemented by searches by NHS Greater Glasgow and Clyde Health Board. Each person was classified as not registered with a GP, not traced, moved out of Health Board area, deceased or registered with a GP. The General Register for Scotland was used to confirm deaths and to check that any who were not traced or were not registered with a GP were not registered as dead. Health Boards were contacted to attempt to trace those that had moved from the Glasgow area. Approval was obtained from the NHS West of Scotland Research Ethics Service.

\section{Recruitment}

The GPs of participants in the 5-7 year follow-up were asked if there was any reason not to contact their patient and if so what that reason might be. A letter inviting participation was then sent to potential participants. If they did not respond after several attempts they were invited to complete the postal version of the Glasgow Outcome Scale-Extended (GOSE). ${ }^{15}$ Those who refused, were not traced or did not respond after several attempts were considered lost to follow-up. Consenting participants were written to or telephoned to arrange a telephone interview.

\section{Assessments}

The existing research database for the 5-7year follow-up provided information on age, gender, medical history pre-injury, cause, severity and characteristics of injury; at 1 and 5-7 years, the GOSE, physical and mental sequelae and at 5-7years psychological and cognitive outcome and alcohol intake. ${ }^{2}$ The 12-14 year follow-up assessment consisted of a telephone interview and the number of follow-up measures was reduced to facilitate recruitment and participation. The main outcome measure was the GOSE. ${ }^{15} 16$ Also included were measures found to have relationships to outcome at 1 year and/or 5-7 years and these were the Perceived Stress Scale, ${ }^{17}$ the Rosenberg Selfesteem Scale ${ }^{18}$ and the Alcohol Use and Dependence Test (AUDIT). ${ }^{19}$ The Hospital Anxiety and Depression Scale ${ }^{20}$ correlated highly with the Perceived Stress Scale and Rosenberg Self-esteem Scale at 5-7 years and were not repeated. The Health Locus of Control (LoC) Scale was given at 5-7years only. ${ }^{21}$ An updated self-report of rehabilitation services received and a self-report of health history were taken. The AUDIT was administered and scored as normal $(<8)$ or high $(>7) .{ }^{19}$ Social deprivation was rated using an index, based on postal address codes. ${ }^{22}$

All interviews were carried out by a senior research nurse (ES) with experience in assessment of head injury. Inter-rater reliability for the GOSE is high. ${ }^{16}$ For this specific study it was assessed on the GOSE in eight cases who were independently rated by telephone by the present (ES) and the previous research worker on the 5-7 year follow-up (LW), ${ }^{2}$ with $100 \%$ concordance found.

\section{Statistical analysis}

Presentation of results is largely descriptive, with frequencies, proportions or means and SDs reported as appropriate. Groups are compared formally using $\chi^{2}$ tests for categorical variables and Mann-Whitney tests or Spearman correlations for continuous variables.

\section{RESULTS}

\section{Characteristics of participants}

Of the 219 survivors at 5-7 years, 90\% were successfully traced at $12-14$ years (see figure 1). Follow-up was achieved in 121/219 (55\%). Those followed-up at 12-14 years consisted of 100 men and 21 women. Mean age at injury was 39 (SD 16) years (range 14-81; quartiles 22, 34 and 47 years). The early features (injury or 1 year follow-up) of those successfully followed-up at 12-14 years were similar to those who were lost to follow-up (table 1). An exception was that a higher proportion aged over 40 years were successfully followed-up $\left(\chi^{2}=4.5, \mathrm{df}=1, \mathrm{p}=0.032\right)$. This reflects a natural relationship between increasing age and increasing risk of mortality. The deceased were easier to followup and were older (23/34 that died between 5-7 and 12-14 years were aged over 40 at injury). If excluding the deceased, age differences in survivors who were followed-up or were lost to follow-up were not significant $\left(\chi^{2}=0.271 ; \mathrm{df}=1 ; \mathrm{p}=0.6029\right)$.

\section{Outcome at $12-14$ years}

Of the 219 people followed up at 5-7 years, 34 (15.5\%) had died. Of the 87 survivors who were followed-up at $12-14$ years, $20 \%$ were severely disabled, 31\% were moderately disabled and 49\% achieved a good recovery. Overall, disability (ie, moderate or severe disability) was found in $51 \%$ of survivors, a rate very similar to that found after 1 (53\%) and 5-7 (53\%) years. A further head injury with loss of consciousness or hospital admission between the original head injury and the 12 year follow-up was reported by $25 / 78$ survivors $(32 \%)$ at $12-14$ years. Self-report of a further head injury was not associated with GOSE at 12-14 years (Mann-Whitney; $z=-1.334$; $\mathrm{p}=0.182$ ), nor was hospital admission for other reasons between 1 and 12-14 years (Mann-Whitney; $z=-0.424 ; p=0.672$ ). At 12-14 years, lower self-esteem (Spearman $r=-0.540, p<0.001$ ) and greater perceived stress (Spearman $r=-0.393, p=0.002$ ) were associated with greater disability on the GOSE.

\section{Outcome at $12-14$ years in relation to pre-injury and 'early' factors}

Outcome (death, severe or moderate disability or good outcome) at 12-14 years was not associated with the pre-injury or 'early" (at injury or 1 year outcome) factors listed in table 2 with the following exceptions. A higher frequency of death or severe disability at $12-14$ years was evident in those aged over 40 years at injury $\left(\chi^{2}=31.992, \mathrm{df}=3, \mathrm{p}<0.001\right)$, or with a history of

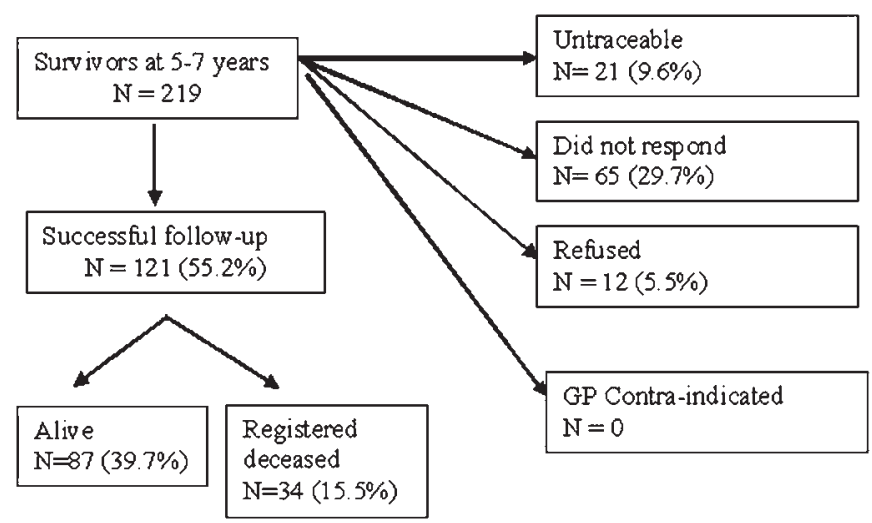

Figure 1 Recruitment at the 12-14 year follow-up. 
Table 1 Comparison of early characteristics of participants followed-up 5-7 years after injury with those in whom follow-up was achieved or not achieved at $12-14$ years

\begin{tabular}{|c|c|c|}
\hline & $\begin{array}{l}\text { Follow-up achieved } \\
\text { (total=121) } \\
N(\%)\end{array}$ & $\begin{array}{l}\text { Lost to follow-up } \\
\text { (total=98) } \\
\mathrm{N}(\%)\end{array}$ \\
\hline \multicolumn{3}{|l|}{ Age at injury } \\
\hline$\leq 40$ years & $71(58.7)$ & $71(72.5)$ \\
\hline$>40$ years & $50(41.3)$ & $27(27.5)$ \\
\hline \multicolumn{3}{|l|}{ Gender } \\
\hline Male & $100(82.6)$ & 77 (78.6) \\
\hline Female & $21(17.4)$ & $21(21.4)$ \\
\hline \multicolumn{3}{|l|}{ Initial severity (GCS) } \\
\hline Mild & 77 (63.6) & $72(73.5)$ \\
\hline Moderate & $24(19.8)$ & $17(17.4)$ \\
\hline Severe & $18(14.9)$ & $7(7.1)$ \\
\hline Missing & $2(1.7)$ & $2(2.0)$ \\
\hline \multicolumn{3}{|l|}{ Previous head injury } \\
\hline No & $63(52.1)$ & $43(43.9)$ \\
\hline Yes & $40(33.0)$ & $27(27.5)$ \\
\hline Missing & $18(14.9)$ & $28(28.6)$ \\
\hline \multicolumn{3}{|l|}{ Previous physical limitations } \\
\hline No & $85(70.2)$ & $64(65.3)$ \\
\hline Yes & $23(19.0)$ & $16(16.3)$ \\
\hline Missing & $13(10.7)$ & $18(18.4)$ \\
\hline \multicolumn{3}{|l|}{ GOSE $\dagger$} \\
\hline Vegetative & $0(0)$ & $0(0)$ \\
\hline Lower SD & $15(12.4)$ & $10(10.2)$ \\
\hline Upper SD & $17(14.0)$ & $10(10.2)$ \\
\hline Lower MD & $28(23.1)$ & $21(21.4)$ \\
\hline Upper MD & $10(8.3)$ & $6(6.1)$ \\
\hline Lower GR & $16(13.2)$ & $11(11.2)$ \\
\hline Upper GR & $35(28.9)$ & $40(40.8)$ \\
\hline \multicolumn{3}{|l|}{ Excessive alcohol use } \\
\hline No & $49(50.0)$ & $55(45.5)$ \\
\hline Yes & $28(28.6)$ & $51(42.1)$ \\
\hline Missing & $21(20.4)$ & $15(12.4)$ \\
\hline \multicolumn{3}{|l|}{ Social deprivation rating* } \\
\hline Lower deprivation $(\leq 7)$ & $67(55.4)$ & $47(48.0)$ \\
\hline Higher deprivation $(>7)$ & $40(33.1)$ & $41(41.8)$ \\
\hline Missing & $14(11.5)$ & $10(10.2)$ \\
\hline
\end{tabular}

*SD rating at injury.

tGOSE at 1 year.

GCS, Glasgow Coma Scale; GOSE, Glasgow Outcome Score-Extended; GR good recovery; MD moderate disability; SD, severe disability.

physical limitations $\left(\chi^{2}=16.099, \mathrm{df}=3, \mathrm{p}<0.001\right)$, and a higher frequency of severe disability was evident in those with other brain illness pre-injury $\left(\chi^{2}=10.524, \mathrm{df}=3, \mathrm{p}=0.015\right)$ (table 2$)$.

Of the 70 participants who were disabled at 1 year, $80 \%$ were disabled or dead at $12-14$ years $(54 \%$ dead). There were 32 people with severe disability at 1 year and of these $53 \%$ had died and only one had a good recovery at $12-14$ years. Of the 51 with a good recovery at 1 year, $20 \%$ had died and $22 \%$ were disabled at 12-14 years. Between 1 and $12-14$ years, the GOSE category remained the same in $32 \%(28 / 87)$; it improved in $34 \%$ and became worse in $34 \%$.

\section{Outcome at $12-14$ years in relation to 'late' outcome 5-7 years after injury}

Mortality between 5-7 and 12-14 years was strongly associated with age over 40 years at injury $\left(50 \%\right.$ vs $13 \% ; \chi^{2}=20.23$, $\mathrm{df}=1, \mathrm{p}<0.001$ ), and not with other factors listed in table 2 . Of those alive at 5-7 years, a higher proportion with severe disability than with moderate disability or a good recovery had died by $12-14$ years $\left(\chi^{2}=64.79 ; p<0.001\right)$. Change in GOSE category (lower or upper severe or moderate disability or good recovery $)^{15}$ between $5-7$ and $12-14$ years occurred in $55 \%$ of survivors. GOSE category improved in 23\% and deteriorated in $32 \%$ (see table 3 for summary). These proportionate changes were similar to those between 1 and 5-7 years in these 87 survivors (between 1 and 5-7 years, GOSE was unchanged in $43 \% ; 31 \%$ improved and $26 \%$ deteriorated).

Normal or high alcohol intake (AUDIT scores above or below 7) at $5-7$ (Mann-Whitney; $z=-1.002 ; p=-0.316)$ or at 12-14 years (Mann-Whitney; $z=-0.687, p=0.492$ ) was not associated with change in GOSE category at 12-14 years. Overall, $63 \%$ of the cohort at $5-7$ years and $56 \%$ at $12-14$ years had high alcohol intake.

If excluding those retired or where data were missing $(n=7$ missing at each time point), $12 \%$ of survivors were unfit for work before the original head injury. The proportion unfit for work increased to $35 \%(27 / 78) 1$ year after injury and changed little thereafter at $5-7$ years $(36 \% ; 26 / 73)$ and $12-14$ years (36\%; 25/69).

Given that the sample sizes for group based analyses are small for examination of psychological variables, distributions of scores are examined using correlations and measures of central tendency are given in table 4 for information. When considering disability outcome, greater disability on the GOSE at $12-14$ years was associated with greater cognitive impairment ${ }^{2}$ (Spearman $\mathrm{r}=0.326, \mathrm{p}=0.003$ ) and poorer psychological health at 5-7 years; that is, greater anxiety (Spearman $\mathrm{r}=-0.402$, $\mathrm{p}=0.001$ ) and depression on the Hospital Anxiety and Depression Scale (Spearman $\mathrm{r}=-0.570, \mathrm{p}<0.001$ ), greater perceived stress (Spearman $\mathrm{r}=-0.356, \mathrm{p}=0.003)$, lower self-esteem (Spearman $\mathrm{r}=-0.453, \mathrm{p}<0.001$ ), and LoC perceived as chance (Spearman $r=-0.342, p=0.004$ ) and powerful others (Spearman $\mathrm{r}=-0.299, \mathrm{p}=0.013$ ) but not as internal control (Spearman $\mathrm{r}=0.038, \mathrm{p}=0.761)$. If death is included as an outcome in the GOSE, the findings are essentially the same (Spearman; cognitive impairment $\mathrm{r}=0.342, \mathrm{p}=0.015$; anxiety $\mathrm{r}=-0.395, \mathrm{p}=0.003$; depression $\mathrm{r}=-0.494, \mathrm{p}<0.001$; perceived stress $\mathrm{r}=-0.291$, $p=0.025$; self esteem $r=-0.455, p<0.001$; chance LoC $r=-0.406$, $p=0.002$; powerful others LoC $r=-0.304, p<0.021$; internal LoC $r=0.053, p=0.694)$.

In contrast with the above, any changes in disability on the GOSE between 5-7 and 12-14 years were not significantly associated with these psychological health measures at 5-7 years (Spearman, $p>0.05$ ), with the exception of LoC, perceived as powerful others which was associated with greater disability on the GOSE at 12-14 years (Spearman $r=-0.259$, $p=0.049$ ). Changes in perceived stress (Spearman $r=0.244$, $\mathrm{p}=0.116$ ) and changes in self-esteem (Spearman $\mathrm{r}=0.009$, $\mathrm{p}=0.955$ ) between $5-7$ and $12-14$ years were not associated with changes in the GOSE between these time points.

\section{Rehabilitation}

Since the 5-7 year follow-up, $27 \%$ of survivors (17/63) reported seeing their GP about the effects of the head injury, and of these almost half $(7 / 17)$ were visits for repeat prescriptions. Only seven had contact with specialist services for brain injury in the past 7 years, with three receiving counselling, one vocational retraining and three attending a support group.

\section{DISCUSSION}

Important strengths of this study are its prospective longitudinal design, that the original cohort was representative of the 
Table 2 Associations between characteristics at injury and outcome at 12-14 years, as measured by the Glasgow Outcome Score-Extended $(n=121)$

\begin{tabular}{|c|c|c|c|c|c|c|c|c|}
\hline & \multirow[b]{2}{*}{$\mathbf{N}$} & \multicolumn{7}{|c|}{ GOSE at $12-14$ year follow-up (\%) } \\
\hline & & Dead & Lower SD & Upper SD & Lower MD & Upper MD & Lower GR & Upper GR \\
\hline \multicolumn{9}{|l|}{ Age at injury } \\
\hline$\leq 40$ years & 71 & 12.7 & 5.6 & 2.8 & 29.6 & 2.8 & 22.5 & 23.9 \\
\hline$>40$ years & 50 & 50 & 10 & 12 & 4 & 4 & 8 & 12 \\
\hline \multicolumn{9}{|l|}{ Gender } \\
\hline Male & 100 & 27 & 8 & 5 & 20 & 4 & 17 & 19 \\
\hline Female & 21 & 33.3 & 4.8 & 14.3 & 14.3 & 0 & 14.3 & 19 \\
\hline \multicolumn{9}{|l|}{ Initial severity (GCS) } \\
\hline Mild (13-15) & 77 & 22.1 & 9.1 & 7.8 & 19.5 & 5.2 & 16.9 & 19.5 \\
\hline Moderate $(9-12)$ & 24 & 37.5 & 4.2 & 4.2 & 12.5 & 0 & 20.8 & 20.8 \\
\hline Severe $(<9)$ & 18 & 38.9 & 5.6 & 5.6 & 27.8 & 0 & 5.6 & 16.7 \\
\hline Missing & 2 & 50 & 0 & 0 & 0 & 0 & 50 & 0 \\
\hline \multicolumn{9}{|l|}{ Previous head injury } \\
\hline No & 63 & 28.6 & 6.3 & 7.9 & 23.8 & 1.6 & 12.7 & 19.0 \\
\hline Yes & 40 & 27.5 & 7.5 & 7.5 & 15 & 5 & 22.5 & 15 \\
\hline Missing & 18 & 27.8 & 11.1 & 0 & 11.1 & 5.6 & 16.7 & 27.8 \\
\hline \multicolumn{9}{|l|}{ Previous physical limitation } \\
\hline No & 85 & 17.6 & 3.5 & 8.2 & 24.7 & 4.7 & 18.8 & 22.4 \\
\hline Yes & 23 & 56.5 & 17.4 & 4.3 & 4.3 & 0 & 8.7 & 8.7 \\
\hline Missing & 13 & 46.2 & 15.4 & 0 & 7.7 & 0 & 15.4 & 15.4 \\
\hline \multicolumn{9}{|l|}{ Previous other brain illness* } \\
\hline No & 94 & 28.7 & 4.3 & 5.3 & 22.3 & 3.2 & 18.1 & 18.1 \\
\hline Yes & 15 & 26.7 & 20 & 20 & 6.7 & 6.7 & 6.7 & 13.3 \\
\hline Missing & 12 & 25.0 & 16.7 & 0 & 8.3 & 0 & 16.7 & 33.3 \\
\hline \multicolumn{9}{|l|}{ Excessive alcohol use } \\
\hline No & 55 & 20.0 & 5.5 & 5.5 & 25.5 & 1.8 & 20.0 & 21.8 \\
\hline Yes & 51 & 39.2 & 7.8 & 9.8 & 11.8 & 5.9 & 9.8 & 15.7 \\
\hline Missing & 15 & 20.0 & 13.3 & 0 & 20.0 & 0 & 26.7 & 20.0 \\
\hline \multicolumn{9}{|l|}{ Social deprivation } \\
\hline Lower deprivation $(\leq 7)$ & 67 & 26.9 & 9 & 10.4 & 16.4 & 3 & 13.4 & 20.9 \\
\hline Higher deprivation $(>7)$ & 40 & 25 & 7.5 & 0 & 25 & 5 & 20 & 17.5 \\
\hline Missing & 14 & 42.9 & 0 & 7.1 & 14.3 & 0 & 21.4 & 14.3 \\
\hline
\end{tabular}

*Mental problems, stroke or other conditions requiring medical attention.

GCS, Glasgow Coma Scale; GOSE, Glasgow Outcome Score-Extended; GR good recovery; MD moderate disability; SD, severe disability.

population of head injury, the careful and consistent approach to the follow-ups, and the use of a well validated and reliable outcome measure. A further strength is the checking and high concordance of ratings between research workers on the GOSE between each follow-up. Inevitably, the sample size has reduced over time, although the rate of recruitment at each stage and the actual sample size remains greater than in many other long term follow-ups, and importantly, has remained representative of the original cohort. However, the sample size 12-14 years after injury is now modest and makes it difficult to exclude type II errors.

Table 3 Glasgow Outcome Score-Extended categories $5-7$ years and $12-14$ years after injury (percentage for $5-7$ years strata in parentheses; $n=121$ )

\begin{tabular}{llcllll}
\hline & \multicolumn{6}{c}{ GOSE at 12-14 years } \\
\cline { 2 - 7 } & & Dead & SD & MD & GR & Total \\
\hline GOSE at 5-7 years & SD & $18(64)$ & $7(25)$ & $3(11)$ & $0(0)$ & 28 \\
& MD & $9(23)$ & $5(13)$ & $19(48)$ & $7(16)$ & 40 \\
& GR & $7(13)$ & $5(9)$ & $5(9)$ & $36(68)$ & 53 \\
& Total & 34 & 17 & 27 & 43 & 121
\end{tabular}

GOSE, Glasgow Outcome Score-Extended; GR good recovery; MD moderate disability; SD, severe disability.
The high occurrence of disability in $51 \%$ of survivors 12-14 years after admission to hospital with a head injury is similar to that found in the same cohort $1^{1}$ and $5-7^{2}$ years after injury. Mortality between injury and 13 years is reported in detail elsewhere for the entire original cohort. ${ }^{14}$ For people that were disabled 1 year after a head injury, the prospect is poor, with four out of five disabled or dead at 12-14 years, even though their median age at injury was only 40 years. Nevertheless, these findings provide further evidence for change in

Table 4 Psychological assessments at 5-7 years and Glasgow Outcome Score-Extended categories at 12-14 years after injury

\begin{tabular}{lrrr}
\hline $\begin{array}{l}\text { Psychological } \\
\text { factors at 5-7 years }\end{array}$ & \multicolumn{4}{l}{ Outcome at 12-14 years } \\
\cline { 2 - 4 } \multicolumn{1}{l}{ Dead } & \multicolumn{1}{l}{ Disabled } & Good recovery \\
\hline Anxiety & $13.1(5.2) ; 11$ & $11.8(4.6) ; 27$ & $8.3(4.6) ; 28$ \\
Depression & $10.7(5.0) ; 11$ & $7.5(3.7) ; 27$ & $4.1(3.3) ; 28$ \\
Perceived stress & $33.6(7.4) ; 10$ & $29.5(9.4) ; 31$ & $24.6(9.6) ; 29$ \\
Self-esteem & $5.0(2.8) ; 11$ & $4.5(2.9) ; 31$ & $2.3(2.4) ; 28$ \\
LoC internal & $23.7(5.8) ; 11$ & $26.2(6.5) ; 30$ & $24.6(5.9) ; 28$ \\
LoC chance & $21.0(7.2) ; 10$ & $21.6(5.5) ; 30$ & $16.6(6.00) ; 28$ \\
LoC powerful others & $20.9(6.7) ; 10$ & $20.3(7.3) ; 30$ & $16.4(5.6) ; 28$ \\
Cognition* & $9.5(4.1) ; 7$ & $8.6(3.5) ; 23$ & $10.9(2.1) ; 27$
\end{tabular}

Values are mean (SD) and N.

*Composite score, see Whitnall et al for details.

LoC, locus of control. 
disability over time, ${ }^{2}$ with GOSE category improving in a third of survivors between 1 and 12-14 years, and even late after injury (between 5-7 and 12-14 years), improvement in GOSE occurred in almost a quarter.

There are few previous studies of outcome 10-15 years after injury against which these findings can be set. Ponsford et al ${ }^{9}$ reported 10-12 year outcome in a sample of 60, recruited between 1992 and 1995. Unlike the present study, most had been injured in a road traffic accident, a minority (20\%) had a mild head injury (GCS) and all had received rehabilitation. Despite the higher proportion of those with mild head injury in the present study, the rates of disability in the two studies are remarkably similar (49\% and 51\%). Although reported rarely, late improvement after head injury is not unknown. Sbordone et $a l^{5}$ interviewed relatives of 20 people 1, 2, 5 and an average of 10 years after severe head injury, and their retrospective reports suggested continuing improvement in social, cognitive, physical and emotional functioning. Thomsen ${ }^{10}$ reported improvement in daily function between 2 and 15 years after severe head injury. Others suggest that late adjustment to persisting disability can have a positive impact on perceived quality of life. ${ }^{723}$ However, these are by no means consistent findings, and Zumstein et al ${ }^{24}$ reported a decline in quality of life between the early and 10 year follow-up after a mild head injury.

The relationships between psychological factors and outcome at 5-7 years and at 12-14 years are intriguing. Thus selfperceptions of higher stress and lower self-esteem were associated with greater disability at 5-7 years and 12-14 years. Similarly, poorer cognitive function, higher anxiety and depression, and perception of control as external at 5-7 years were each associated with greater disability at $12-14$ years. What these data do not easily capture is causality, as disability outcome was established for many by $5-7$ years when these psychological measures were first given. A case for causality might be made by evidence for relationships between scores on psychological measures at 5-7years and change in disability between $5-7$ and $12-14$ years. The most clear and significant finding here was that an externalised perception of control by others at $5-7$ years was associated with increases in disability between 5-7 and 12-14 years. Although the limited sample size limits the confidence in this finding and its interpretation, it may not simply reflect a persisting self-perception of disability relatively soon after injury as being disempowering, because there was no significant association between disability outcomes at 1 year and LoC as powerful others at 5-7 years (Spearman $r=0.037 ; p=0.782)$. Instead these data imply that whereas greater disability after head injury is associated with greater psychological distress at 5-7 years and 12-14 years after injury, changes in disability between these times are associated more strongly with a perception of externalised control. This may reflect an association between a belief that outcomes in life are controlled by others (such as health professionals, family or friends) and deterioration in outcome. In order to produce sustained improvements in disability outcome after head injury, addressing self-perceptions of control may be more important than interventions for complaints about distress and loss of self-esteem as these may be a consequence of beliefs about external LoC. ${ }^{25}$ LoC has been ranked as one of the three most highly investigated traits in personality research, ${ }^{26}$ but little research has been published about LoC and treatment of head injury. One retrospective study compared outcome in 37 people with brain injury 12-22 years after receiving rehabilitation with 13 brain injured people who had not received rehabilitation. In the rehabilitation group, there were perceptions of greater internal LoC, higher self-efficacy, less psychological distress and better quality of life. ${ }^{27}$ In contrast, few people in our cohort received rehabilitation at any time after injury. ${ }^{12}$

Our findings underline the dynamic nature of disability after head injury, the need to understand the factors involved and the importance of finding ways to influence these for a considerable time after injury. Features that predate the injury or that are reflections of acute severity do not seem relevant at this late stage and in these data were not important. Thus disability and change in outcome were not explained by factors extraneous to the original head injury, such as advancing age, hospitalisation for further cerebral or other injury, alcohol use or social deprivation, or by indices of early severity. The range of interventions that has been proposed is broad, evidence of their effectiveness is limited and further approaches are needed. ${ }^{28}$ Our identification of the important influence of self-perception of control late after injury therefore has important implications.

In conclusion, the high overall rate of disability (51\%) reported in this cohort at 1 year and at 5-7years persists 12-14 years after injury. This reflects a balance between disability outcome improving (23\%), worsening (32\%) and remaining unchanged (45\%). Given that changes are dynamic in many for up to 14 years after head injury, the association between self-perception of control and late changes in outcome deserve further investigation with a view towards beneficial intervention.

Acknowledgements Thanks are due to Dr Christopher Weir, senior lecturer in statistics, for advice on a draft of this manuscript.

Contributors All authors met the following contributor criteria: (1) substantial contributions to concept and design, acquisition of the data, or analysis and interpretation of the data; (2) drafting the article or revising it critically for important intellectual content; and (3) final approval of the version to be published.

Competing interests None.

Ethics approval Ethics approval was provided by NHS West of Scotland Research Ethics Service.

Provenance and peer review Not commissioned; externally peer reviewed.

\section{REFERENCES}

1. Thornhill S, Teasdale GM, Murray GD, et al. Disability in young people and adults one year after head injury: prospective cohort study. BMJ 2000:320:1631-5.

2. Whitnall L, McMillan TM, Murray G, et al. Disability in young people with head injury: a 5-7 year follow-up of a prospective cohort study. J Neurol Neurosurg Psychiatry 2006;77:640-5.

3. Asikainen I, Kaste M, Sarna S. Predicting late outcome for patients with traumatic brain injury referred to a rehabilitation programme: a study of 508 Finnish patients 5 years or more after injury. Brain Inj 1998;12:95-107.

4. Rappaport M, Herrero-Backe C, Rappaprort ML, et al. Head injury outcome upt to 10 years later. Arch Phys Med Rehabil 1989;70:885-92.

5. Sbordone RJ, Liter JC, Pettler-Jennings P. Recovery of function following severe TBI: a retrospective 10-year follow-up. Brain Inj 1995;9:285-9.

6. Hoofien D, Vakil E, Gilboa A et al. Comparison of the predictive power of socioeconomic variables, severity of injury and age on long term outcome after traumatic brain injury. Brain Inj 2002;16:9-27.

7. Wood RL, Rutterford NA. Psychosocial adjustment 17 years after severe brain injury. J Neurol Neurosurg Psychiatry 2006;77:71-3.

8. Engborg AW, Teasdale TW. Psychosocial outcome following TBI in adults: a long term population based follow-up. Brain Inj 2004;18:533-45.

9. Ponsford J, Draper K, Schonberger M. Functional outcome 10 years after traumatic brain injury: Its relationship with demographic, injury severity and cognitive and emotional status. J Int Neuropsychological Soc 2008;14:233-42.

10. Thomsen IV. Late outcome of very severe blunt head trauma: a 10-15 year second follow-up. J Neurol Neurosurg Psychiatry 1984;47:260-8.

11. Johnson R. How do people get to work after severe head injury? A 10 year follow up study. Neuropsychol Rehabil 1998;8:61-9.

12. Hammond FM, Grattan KD, Sasser H, et al. Five years after traumatic brain injury: a study of individual outcomes and predictors of change in function. Neurorehabilitation 2004;19:25-35

13. McMillan TM, Teasdale GM. Death rate is increased for at least 7 years after head injury: a prospective study. Brain 2007;130:2520-7. 
14. McMillan TM, Teasdale GM, Weir C, et al. Death after head injury. The 13 year outcome of a case-control study. J Neurol Neurosurg Psychiatry 2011;82:931-5.

15. Wilson JT, Pettigrew LE, Teasdale GM. Structured interviews for the Glasgow Outcome Scale and the extended Glasgow Outcome Scale. Guidelines for their use. J Neurotrauma 1998;15:573-85.

16. Pettigrew LE, Wilson JT, Teasdale GM. Reliability ratings on the Glasgow Outcome Scales from in-person and telephone structured interviews. J Head Trauma Rehabil 2003;18:252-8

17. Cohen S, Kamarck T, Mermelstein R. A global measure of perceived stress. J Health Soc Behav 1983;24:385-96.

18. Rosenberg M. Society and the adolescent self-image (reprint edition). Middletown, CT: Wesleyan University Press, 1989

19. Babor TF, Ramon de la Fuente J, Saunders J, et al. AUDIT: The Alcohol Use Disorders Test: Guidelines for use in primary care. Geneva: World Health Organisation (WHO), 1992.

20. Snaith RP, Zigmond AS. The Hospital Anxiety and Depression Scale. Berkshire: NFER-NELSON, 1994

21. Wallston KA, Wallston BA. 'Health locus of control scales'. In: Lefcourt $H$, ed Research with the Locus of Control Construct, vol. 1: assessment methods. New York: Academic Press, 1978.
22. Scottish Executive. Fair Shares for All: Final Report. National Review of Resource Allocation. Edinburgh: Scottish Executive, 2000

23. Brown AW, Moessner AM, Mandrekar J, et al. A survey of very long outcomes after traumatic brain injury among members of a population based incident cohort. J Neurotrauma 2011;28:167-76.

24. Zumstein MA, Moser M, Mottini M, et al. Long term outcome in patients with mild traumatic brain injury: a prospective observational study. J Trauma 2011;71:120-7.

25. Walker J. Control and the psychology of health. Buckingham UK: Open University Press, 2001.

26. Judge TA, Erez A, Bono JE, et al. Are measures of self-esteem, neuroticism, locu of control and generalised self-efficacy indicators of a common core construct? J Personality Soc Psychol 2002;83:693-170

27. Svendsen HA, Teasdale TW. The in uence of neuropsychological rehabilitation on symptomatology and quality of life following brain injury: a controlled long-term follow-up. Brain Inj 2006;20:1295-306.

28. Turner-Stokes L, Nair A, Sedki I, et al. Multi-disciplinary rehabilitation for acquired brain injury in adults of working age. Cochrane Database Syst Rev 2005;3:CD004170. 